\title{
Definición del objeto de trabajo y conceptualización de los Siste- mas de Información Audiovisual de la Televisión
}

\author{
Inés-Carmen Póveda-López * \\ Jorge Caldera-Serrano ** \\ Juan-Antonio Polo-Carrión ***
}

Artículo recibido:

9 de noviembre de 2009.

Artículo aceptado:

2 de marzo de 2010.

\section{RESUMEN}

Se define el objeto de trabajo documental en los sistemas de información audiovisual de la televisión, partiendo de las distintas definiciones aportadas por los principales autores e instituciones sobre los conceptos de audiovisual, imagen en movimiento, sonido, documentación audiovisual, información audiovisual y documento audiovisual. Se llega así, por medio de la cuantificación y el análisis de las ideas y conceptos más repetidos en las definiciones analizadas, a definir un "Documento televisivo de imagen en movimiento".

* Canal Extremadura Televisión, España. icpovlop@alcazaba.unex.es

** Universidad de Extremadura, España. jcalser@alcazaba.unex.es

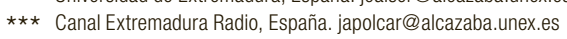

INVESTIGACIÓN BIBLIOTECOLÓGICA, Vol. 24, Núm. 50, enero/abril, 2010, México, ISSN: 0187-358X. pp. 15-34 
Palabras clave: Televisión; Objeto de trabajo; Análisis conceptual; Audiovisual; Imagen en movimiento

\begin{abstract}
Defining the object of work and conceptualizing TV Audiovisual Information Systems

Inés-Carmen Póveda-López; Jorge Caldera-Serrano and Juan-Antonio Polo-Carrión

The object of documentary work in visual information systems on TV is defined on the basis of the various ideas provided by leading authors and institutions about the concepts of audiovisual, moving image, sound, audiovisual documentation, audiovisual information and audiovisual document. This takes us through quantification and analysis of the most recurrent ideas and concepts discussed in the studied definitions.
\end{abstract}

Keywords: TV / Work object; Conceptual analysis; Audiovisual; Moving image

\title{
I. TeLevisión Y DOCUMENTACIÓN
}

U n arquitecto estadunidense llamado Frank L. Wright (1867-1959) dijo que "la televisión es goma de mascar para los ojos", y no le faltaba razón. Podemos afirmar que nos encontramos en la era de la televisión, y que ésta está siendo potenciada por los nuevos medios de acceso a la TV a través de la Red, ya que este medio de comunicación se ha hecho tan popular que ha llegado a convertirse en cierto modo en el eje de la sociedad.

Se trata de una ventana al mundo, a la información y, sobre todo, al entretenimiento, de tal forma que las diferentes cadenas de televisión se centran casi en exclusividad por lograr este último aspecto. La televisión se ha convertido en poco más de 50 años de vida en uno más de la familia.

En gran medida esto se debe a diversos factores que hacen de la televisión un medio especialmente atractivo, entre los cuales encontramos su carácter audiovisual y su forma de percepción. Esto por supuesto no ha pasado inadvertido a las empresas televisivas, las que han encaminado su política hacia 
la consecución de mayor audiencia, rentabilizando sus gastos por medio de ingresos publicitarios multimillonarios.

La gran cantidad de material generado por y para la televisión ha sido una preocupación constante. Por ello desde un primer momento estas empresas vieron la necesidad de que la documentación fuera controlada de manera que se pudiera reutilizar de forma adecuada.

En este punto entran en juego los Sistemas de Información Documental de las televisiones con un prisma absolutamente empresarial, y con objetivos concretos: realizar su labor profesional analizando y controlando diversos tipos de material, en diferentes soportes, formatos, formas y modos de producción y difusión. Para poder optimizar la ingente cantidad de información producida cuentan con cuatro subsistemas para gestionar la información documental. Entre estos Sistemas de Información Televisivos podremos encontrar el Sistema de Información Documental Sonoro, el Sistema de Información Documental Textual, el Sistema de Información Documental Fotoperiodístico y el Sistema de Información Documental Audiovisual, siendo este último el más importante y esencial para las empresas televisivas.

\section{Hacia El objeto de trabajo}

Son muchos los aspectos que se han estudiado dentro de los sistemas de información televisivos: cómo se estructuran; aspectos derivados de la determinación de la cadena documental — con más o menos detalle e incluso con alguna laguna-, y el origen de esta documentación y/o su utilización, son sólo algunos de los diferentes parámetros que han sido estudiados para mejorar la praxis profesional de estos Servicios de Información. No obstante, aún son muchos los esfuerzos que deben desarrollarse en esta labor investigadora de todos los ámbitos de la gestión documental.

Ante el sistema de información documental audiovisual nos encontramos con una tipología documental que cuenta con una serie de características que la hacen peculiar, caracterizándola e individualizándola. Es el caso del término audiovisual, relativamente nuevo y que cuenta con muchas definiciones, no todas las cuales le atribuyen el mismo significado. Esto implica que bajo el término audiovisual se aglutina una gran cantidad de materiales que, dependiendo de la corriente conceptual que escojamos, se considerará como una cosa o la otra.

La misma naturaleza de esta documentación hace que existan enormes diferencias entre los documentos con los que trabaja este sistema, e igualmente el tratamiento que reciben no es uniforme sino que está sujeto a diferentes 
criterios y, como consecuencia, se incluyen distintos niveles de profundidad a la hora de describir dicha documentación.

Partiendo de todas estas peculiaridades, y de la especificidad de dicha documentación, estableceremos cuál es el término más adecuado para denominar el objeto de trabajo que existe en los sistemas de información documental audiovisual.

\section{Metodología del estudio}

El método utilizado es lo que Ezequiel Ander-Egg (1995) denomina investigación pura, ya que

es la que se realiza con el propósito de acrecentar los conocimientos teóricos para el progreso de una determinada ciencia, sin interesarse directamente en sus posibles aplicaciones o consecuencias prácticas; es más formal y persigue propósitos teóricos en el sentido de aumentar el acervo de conocimientos de una determinada teoría.

Para llegar al objeto de trabajo se ha realizado una revisión bibliográfica encaminada a extraer, de diversas fuentes, definiciones sobre los conceptos que están íntimamente relacionados con él: audiovisual, sonido, imagen en movimiento, documentación audiovisual, información audiovisual y documento audiovisual.

De cada uno de estos conceptos hemos recogido las definiciones aportadas por los autores, entidades y organismos más representativos de la materia, para, a partir de su análisis, extraer los términos más destacados de cada enunciado y establecer una serie de elementos comunes a estas definiciones, de manera que sepamos cuáles son los términos imprescindibles al momento de definir los distintos conceptos.

Partiendo de la revisión bibliográfica que se propone realizar un análisis de las definiciones que se observan con el fin de extraer los elementos conceptuales presentes, se lleva a cabo una cuantificación de los elementos resultantes útiles para definir el objeto de trabajo en televisión. Estos elementos se unen con aquellos conceptualmente equivalentes y de este modo crean una ponderación basada en los elementos conceptuales más repetidos en las definiciones relacionadas con el objeto de trabajo. Esto finaliza uniendo los términos más significativos en una nueva definición que aporta el objeto de trabajo analizado en las televisiones. 


\section{Definiciones de conceptos Relacionados \\ CON EL OBJETO DE TRABAJO EN LAS TELEVISIONES}

Realizaremos una exposición de cada una de las definiciones que han sido analizadas aquí para alcanzar una definición del objeto de trabajo.

\subsection{Concepto de "Audiovisual":}

Real Academia de la Lengua (2001):

Audiovisual es aquello que se refiere al oído y a la vista o los emplea a la vez. Se dice especialmente de métodos didácticos que se valen de grabaciones acústicas acompañadas de imágenes ópticas.

Cebrián Herreros, Mariano (1995):

Con el término audiovisual se abarcan medios que llegan por lo auditivo, como la radio: por lo visual, como la diapositiva; o por la combinación de ambos: cine y televisión.

\section{SEAPAVAA (1996):}

Audiovisual se refiere a las imágenes en movimiento y/o a los sonidos grabados, registrados en película, cinta magnética, disco o cualquier otro medio actualmente conocido o por inventar.

UNESCO (1970):

Abarca por igual las imágenes en movimiento y los sonidos grabados de todo tipo. Se designa para agrupar los campos de los archivos cinematográficos, de televisión y de sonidos, los cuales, aunque tienen origen diverso, han ido encontrando puntos en común mediante el cambio tecnológico.

IFLA (2004):

Relativo a la vista y/o sonido.

García Ejarque, Luis (2000):

Que es perceptible por el oído y la vista a la vez.

López Yepez, José (2004):

Es todo recurso o soporte en los que se combinan simultáneamente audio y video en medios como el cine, la televisión y otros sistemas de carácter didáctico, que utiliza grabaciones acústicas acompañadas de imágenes. 
Victoria University of Wellington (2006):

Items that are not in paper form such as videos, CD-ROMs, DVD's, microfilm and cassettes.

Pearce-Moses, Richard (2005):

Having sound and pictorial attributes, especially when combined. The processes and materials used to capture, record, transmit, or reproduce sound or images.

Reitz, Joan M (2004):

A work in a medium that combines sound and visual images, for example, a motion picture or videorecording with a sound track, or a slide presentation synchronized with audiotape.

Aquellos elementos que más se repiten son, por orden de mayor a menor, simultaneidad de imagen y sonido, imagen en movimiento, registro sonoro (sonido), percepción por oído y vista, posibilidad de que no aparezca sonido, imagen fija, soporte físico, carácter didáctico y procesos documentales.

De esta manera una definición de audiovisual debería abarcar tanto las imágenes, ya sean en movimiento (7) o fijas (4), como los sonidos (6) de manera simultánea (9), aunque se contempla la posibilidad de que éstos no aparezcan (4), que son perceptibles por los sentidos del oído y la vista (4) y que están contenidos en un soporte físico (3).

\subsection{Concepto "Imagen en movimiento":}

Abad Tejerina, María Jesús (1999):

A diferencia de la imagen fija, la imagen en movimiento implica irremediablemente tiempo, por lo que una secuencia de imágenes da lugar a un suceso, entendiéndolo como un discurso en el tiempo. La imagen en movimiento se adapta mejor a la realidad porque nos resulta más verosímil. El ojo es un mecanismo que reacciona, sobre todo, al estímulo del movimiento; podríamos considerarlo el más importante de los sentidos en cuanto a la percepción del entorno se refiere. Nuestros mecanismos de alerta entran en acción en cuanto percibimos movimiento. La imagen en movimiento atrae poderosamente nuestra atención, deseamos que el hecho se prolongue. Tratamos de adivinar cómo continúa, es decir crea adicción. Una imagen en movimiento se extingue en el momento en que la vemos. En algún sentido es más parecida al sueño, carecemos de expectativas para actuar, nos convierte en sujetos pasivos. Como en el sueño no podemos cambiar los hechos, es una función intransitiva, y 
al igual que en ellos jugamos un papel absolutamente pasivo. Siempre queremos ver más, queremos soñar.

Méndez, Jorge (1997):

En la imagen en movimiento, lo que percibimos esencialmente es un movimiento debido a la persistencia de la imagen en la retina, hecho que nos permite percibir movimiento ante una sucesión rápida de imágenes fijas, como en el caso del cine o de líneas, como en la televisión.

Dublin Core (2003):

A series of visual representations that, when shown in succession, impart an impression of motion. Examples of moving images are: animations, movies, television programs, videos, zoetropes, or visual output from a simulation

DCMI:

Any image created in a film, video, or other media format that alters with time and that is able to be displayed or projected on a screen. For example, movies, animations, television, multimedia, games, emerging media, simulations.

López Yepez, José (2004):

La que se representa de este modo, caso del cine y de la televisión.

Knight, Gareth; McHugh, John (2005):

Moving image data is composed of a sequence of still images that, when shown in succession, create the impression of motion. It is often accompanied by audio that may be synchronised with a specific time point. Examples of moving images include animations, movies, television programs, and other visual output.

Pearce-Moses, Richard (2005):

A generic term for a visual work that has the appearance of movement.

Los elementos más representativos serían, de mayor a menor, la apariencia de movimiento, la sucesión de imágenes fijas, el aspecto temporal, un reflejo de la realidad, la persistencia retiniana y la posible sincronización con sonidos.

Así, una posible definición de imagen en movimiento partiendo de estos elementos sería: una sucesión de imágenes fijas (3) que dan (producen) sensación de movimiento (5). 


\subsection{Concepto "Sonido":}

López Thome, Emilio (2000):

Registro de cualquier sonido (música, voz humana, etc.) en un soporte físico que permite su conservación y reproducción mediante equipos técnicos adecuados.

Ley de la Propiedad intelectual:

Fijación exclusivamente sonora de la ejecución de una obra o de otros sonidos.

López Yepez, José (2004):

El que requiere el uso de un equipo adecuado para poder ser escuchado.

IASA (2005):

Se llama grabación sonora a la fijación de todo tipo de sonidos de alguna forma material permanente, que permite que se puedan escuchar, reproducir, emitir por radiotelevisión o comunicarse rápidamente.

Caldera Serrano, Jorge; Nuño Moral, María Victoria (2004):

Aquel que se percibe por el sistema auditivo.

Los elementos que más aparecen en las diferentes definiciones (de mayor a menor) son registro sonoro, cuya finalidad es la conservación, la necesidad de contar con un equipo apropiado para poder escuchar el contenido, realizar la fijación en un soporte físico, la percepción y la finalidad de comunicación del contenido y su difusión..

De esta manera un documento o registro sonoro será el registro o fijación del sonido (3) en un soporte físico (2) que permita su conservación (2) y reproducción mediante un equipo adecuado (2).

\subsection{Concepto "Información audiovisual":}

Sanabria, Francisco (1994):

Es aquella que les llega a los receptores por medio de sonidos e imágenes, lo que exige una codificación adecuada a los signos que utilizan y un canal capaz de usarlos.

Cebrián Herreros, Mariano (1995):

La información audiovisual congrega los elementos perceptivos y afectivos de las imágenes y los sonidos y los elementos conceptuales propios de las palabras 
orales y escritas. [...] Imagen y palabra se interrelacionan y se apoyan para resolver carencias que cada subsistema tiene por sí solo. Ya no cabe aludir a una información perceptiva y a una información conceptual. En la información audiovisual se concentran las dos dimensiones.

Aunque muchos autores hablan de la información audiovisual, pocos son los que la definen. En este caso las dos definiciones tienen una serie de elementos comunes como son la presencia de imágenes y sonidos (incluyendo voz, música o ruido), también se destaca la necesidad de realizar una correcta codificación del mensaje que permita el aumento de la eficacia comunicativa, y la presencia de un canal por el que éste se transmita.

Corral Baciero (1989):

habla de la "información televisual" para referirse a la información que se transmite por este medio, destacando que la instantaneidad que lo caracteriza permite acercar las noticias hasta los espectadores, pero dándole aún más importancia a la realimentación que existe en la programación; es decir, a la utilización de material audiovisual generado con anterioridad. Las empresas deben por tanto conservar su documentación audiovisual con el fin de poder ser éste explotado comercialmente o en la producción de la parrilla programática de la cadena.

\subsection{Concepto "Documentación audiovisual":}

López Yepes, Alfonso (1992):

Ciencia que tiene por objeto el estudio del proceso de comunicación de las fuentes audiovisuales para la obtención de nuevo conocimiento aplicado a la investigación y el trabajo audiovisual.

Hernández Pérez, Antonio (1992.): Define la documentación audiovisual como aquel conjunto de mensajes cuyo contenido lo constituyen básicamente imágenes en movimiento acompañadas, de forma más o menos sincrónica, por elementos del sistema sonoro — voces, música, ruidos—.

Alfonso i Noguerol, Lola (1999). Nos muestra la siguiente definición:

La documentació audiovisual podria considerarse com aquell conjunt de missatges el contingut dels quals el constitueixen básicament imatges en moviment (banda imatge) acompanyades per element del sistema sonor: veus, música, sorolls (banda so).

Traducción: la documentación audiovisual podría considerarse como aquel conjunto de mensajes que constituyen básicamente imágenes en movimiento 
(banda imagen) acompañadas por elementos del sistema sonoro: voz, música, sonidos (banda sonido).

Corral Baciero, Antonio (1989). La documentación periodística audiovisual se define

como aquella parte de la documentación que se encarga del estudio del proceso documental —básicamente, selección, análisis, almacenamiento, conservación, búsqueda, recuperación y difusión- de aquellos mensajes cuyo contenido se refiere a información de actualidad y que son transmitidos por medios audiovisuales, esto es, que son percibidos a un tiempo por el receptor por medio del sistema visual y del sistema auditivo. Normalmente se presenta en forma de imágenes en movimiento acompañadas por un fondo sonoro (discurso verbal, música, silencio o efectos sonoros naturales o artificiales) y admiten la existencia, en medio del mensaje, de otros tipos de códigos, como son las imágenes fijas (representativas o simbólicas) o los signos escritos, y son conservados en soporte óptico o magnético.

López Yepez, José (2004):

Comprende la selección, el análisis, la elaboración y la utilización de los diferentes contenidos que conforman el concepto audiovisual. Aquellos documentos que se elaboran para ser utilizados en centros, empresas e instituciones que trabajan con material audiovisual.

Agirreazaldegi Berriozabal, Teresa (1996):

Denominamos documentación audiovisual a las grabaciones audiovisuales producidas con anterioridad y de forma independiente, en el tiempo y en la intencionalidad directa, al hecho noticioso en el que van a ser o podrían ser integradas.

Los elementos más representativos, de mayor a menor, serían: conjunto de mensajes, imágenes en movimiento, registro sonoro, sincronización, proceso documental, información de actualidad, ciencia, parte de la Documentación, transmisión por medios audiovisuales, grabaciones audiovisuales, percepción por oído y vista e imágenes fijas.

Encontramos dos vertientes respecto a la definición, por lo que tendríamos dos posibles definiciones. De esta manera la primera posible definición de Documentación Audiovisual sería: el conjunto de mensajes (3) cuyo contenido son las imágenes en movimiento (3), que contemplan la posibilidad de ser fijas (1), sincronizadas (2), con sonidos (3) y que son perceptibles por los sentidos del oído y la vista (1). Y por otro lado: Ciencia (1) o parte de la 
Documentación (1) que se encarga del estudio de lo relativo al audiovisual y de los procesos documentales (2), de su transmisión (1) y de su contenido (información de actualidad (1)).

\subsection{Concepto "Documento audiovisual":}

Valle Gastaminza, Félix del (2004). Documentos audiovisuales son:

Registros visuales (con o sin banda sonora), independientemente de su soporte físico, y procesos de registro o grabación, como películas, microfilms, diapositivas, cintas magnéticas, videogramas, laserdiscs, CD-Rom, a) realizados para difusión pública a través de la radio o la TV, por medio de proyección en pantalla o por cualquier otro medio, b) realizados para ser puestos a disposición del público.

Registros sonoros, independientemente de su soporte físico y proceso de registro o grabación, como cintas magnéticas, discos, bandas sonoras, laserdiscs, a) realizados para difusión pública a través de la radio, o por cualquier otro medio, b) realizados para ser puestos a disposición del público.

Los documentos audiovisuales son obras que comprenden imágenes reproducibles y/o sonidos incorporados a un soporte: cuya grabación, transmisión, percepción y comprensión requiere generalmente de algún equipo tecnológico; cuyo contenido visual y/o sonoro tiene una duración lineal; y cuyo propósito es la comunicación de ese contenido.

Rodríguez Bravo, Blanca (2004):

Documento audiovisual es aquel que en un mismo soporte contiene imágenes en movimiento —información visual— y sonido, sin distinción de soporte físico ni de forma de grabación, y que requiere un dispositivo tecnológico para su grabación, transmisión, percepción y comprensión. Se caracteriza pues por su dualidad o carácter mixto, su diacronía que le viene dada por el canal audio, y su opacidad que le hace ser dependiente de la tecnología para el acceso al contenido.

Ley de la propiedad intelectual:

Se entiende por grabaciones audiovisuales las fijaciones de un plano o secuencia de imágenes, con o sin sonido, sean o no creaciones susceptibles de ser calificadas como obras audiovisuales en el sentido del artículo 86 de esta Ley.

Ojeda Castañeda, Gerardo (1992):

Todos aquellos materiales que se deseen conservar de modo permanente como parte integrante de un acervo, una colección o un fondo previamente establecido. 
García Ejarque, Luis (2000):

Dícese del documento o del material que precisa de un aparato específico para percibir a la vez, por el oído y la vista, el mensaje que encierra.

López Yepez, José (2004):

El que requiere el uso de un equipo audiovisual para ser visto o escuchado, por sus contenidos de imagen y sonido. Se refiere, en general, a documentos relativos a programas de cine y televisión.

IASA (2005)

Cualquier documento que contenga sonido y/o imágenes móviles o fijas.

Núñez Fernández, Eduardo (1999):

Documentos audiovisuales: son documentos de archivo que transmiten su contenido mediante la combinación de imagen y sonido, con dos excepciones: la imagen puede ser fija o en movimiento y, en algunos casos, la imagen no va acompañada de sonido. Entrarían dentro de esta categoría las películas mudas y sonoras, los videodiscos y los videocasetes.

Por orden de mayor a menor en el número de veces que se repite, el elemento quedaría de la siguiente forma: registro sonoro, imagen en movimiento, simultaneidad de imagen y sonido, necesidad de un equipo de reproducción, posibilidad de que no aparezca sonido, soporte físico, imágenes fijas, finalidad de difusión, finalidad de conservación, diacronía, dualidad, finalidad de comunicación del contenido, opacidad, percepción por los sentidos del oído y la vista.

Una posible definición de documento audiovisual atendiendo a los elementos anteriores sería: registro de imágenes en movimiento (5) y sonidos (6) (con la posibilidad de que no aparezca la banda de sonido (4) y de que las imágenes sean fijas (2)) de manera simultánea (5), en un soporte físico (3) cualquiera que éste sea, cuya finalidad sea la difusión (2), comunicación (1) y conservación del contenido (1), para lo cual será necesario un equipo adecuado (4). Se destacan como características de estos documentos la dualidad (1), la diacronía (1) y la opacidad (1).

\section{ANÁlisis de los Resultados y Definición DEL ObJeto DE TRABAJO}

Desde que se tomó conciencia de la importancia de la televisión como método de transmisión y consumo de información en nuestra sociedad, se hizo 
patente la necesidad de gestionar todo el material que emitían o que llegaba al centro, independientemente de la procedencia, forma, formato y fin programático. El papel que adquieren en esto los Servicios de Documentación Audiovisual es fundamental para que todo pueda realizarse de forma correcta.

La elección del término a definir (Documento de imagen en movimiento televisivo) como objeto de trabajo en las televisiones está motivada por los siguientes aspectos:

a) Organismos como la UNESCO que se refieren al patrimonio audiovisual con el término imagen en movimiento, sin perjuicio de que pueda aparecer la banda de sonido, pero que le otorga mayor valor a la banda de imagen; el ejemplo más claro lo encontramos en el título "Recomendación para la salvaguarda y conservación de imágenes en movimiento". De igual forma lo hacen diversos autores como Orozco García-Mayorca (1998), Caldera Serrano (2003), o Caldera Serrano y Nuño Moral (2002, 2004).

b) Los documentos con los que nos encontramos en un centro de documentación de televisión pueden no contar con la banda de sonido y no por ello pierden su carácter televisivo; sin embargo si no aparece la banda imagen serán considerados documentos sonoros, por esta razón se prefiere el término de imagen en movimiento contemplando la posibilidad de que aparezca la banda de sonido.

c) El análisis cualitativo de las definiciones realizadas por los autores relacionados de una forma directa con los medios de comunicación televisivos, ya sea desde el punto de vista profesional, universitario y/o de investigación.

Una vez que hemos establecido cuál es el término que mejor se ajusta al objeto de trabajo nos hemos centrado en definirlo, para lo que nos hemos apoyado en aquellos términos que se encuentran íntimamente relacionados con él; audiovisual, imagen en movimiento, sonido, documentación audiovisual, información audiovisual y por último documento audiovisual.

Se han analizado de forma individual cada uno de estos términos y hemos obtenido una serie de elementos que resumiremos en la siguiente tabla, de forma que la primera columna incluirá los elementos extraídos y la primera fila los conceptos.
Concepto 1:
Audiovisual
Concepto 2:
Imagen en movimiento
Concepto 3:
Sonido 
Concepto 4:

Concepto 5:

Concepto 6:
Documentación audiovisual

Información audiovisual

Documento audiovisual

De esta manera podremos establecer cuáles son los elementos que se repiten. El dato de la última columna se corresponde con el porcentaje que representa el número de veces que encontramos cada elemento respecto al total de las definiciones, para ello partimos de un total de 37 definiciones.

\begin{tabular}{|l|l|l|l|l|l|l|l|c|}
\hline \multicolumn{1}{|c|}{ Elementos/concepto } & $\mathbf{1}$ & $\mathbf{2}$ & $\mathbf{3}$ & $\mathbf{4}$ & $\mathbf{5}$ & $\mathbf{6}$ & Total & $\mathbf{\%}$ \\
\hline Apariencia de movimiento & & $\mathbf{5}$ & & & & & 5 & 13,5 \\
\hline Aspecto temporal & & 1 & & & & & 1 & 3,7 \\
\hline Carácter didáctico & 2 & & & & & & 2 & 5,4 \\
\hline Ciencia & & & & & 1 & & 1 & 3,7 \\
\hline Codificación & & & & 1 & & & 1 & 3,7 \\
\hline Conjunto de mensajes & & & & & 3 & & 3 & 8,1 \\
\hline Diacronía & & & & & & 1 & 1 & 3,7 \\
\hline Dualidad & & & & & & 1 & 1 & 3,7 \\
\hline $\begin{array}{l}\text { Finalidad comunicación del } \\
\text { contenido }\end{array}$ & & & 1 & & & 1 & 2 & 5,4 \\
\hline Finalidad de conservación & & & 2 & & & 1 & 3 & 8,1 \\
\hline Finalidad la difusión & & & 1 & & & 1 & 2 & 5,4 \\
\hline Imagen en movimiento & 7 & & & 2 & 3 & 5 & 17 & 45 \\
\hline Imagen fija & 4 & & & 1 & & 2 & 7 & 19 \\
\hline Posibilidad sin sonido & 4 & & & & & 4 & 8 & 21 \\
\hline $\begin{array}{l}\text { Necesidad equipo de } \\
\text { reproducción }\end{array}$ & & & 2 & & & 4 & 6 & 16,2 \\
\hline Opacidad & & & & & & 1 & 1 & 3,7 \\
\hline Parte de la documentación & & & & & 1 & & 1 & 3,7 \\
\hline Percepción por oído y vista & 4 & & 2 & & 1 & 1 & 8 & 21 \\
\hline Persistencia retiniana & & 1 & & & & & 1 & 3,7 \\
\hline $\begin{array}{l}\text { Procesos documental y } \\
\text { materiales }\end{array}$ & 1 & & & & 2 & & 3 & 8,1 \\
\hline Reflejo de la realidad & & 1 & & & & & 1 & 3,7 \\
\hline Registro sonoro - sonido & 6 & & & 2 & 3 & 6 & 17 & 45 \\
\hline $\begin{array}{l}\text { Simultaneidad o sincroniza- } \\
\text { ción de imagen y sonido }\end{array}$ & 9 & 1 & & 1 & 2 & 5 & 18 & 49 \\
\hline Soporte físico & 3 & & 2 & & & 3 & 8 & 21 \\
\hline Sucesión de imágenes fijas & & 3 & & & & & 3 & 8,1 \\
\hline $\begin{array}{l}\text { Transmisión por medios } \\
\text { audiovisuales }\end{array}$ & & & & & 1 & & 1 & 3,7 \\
\hline
\end{tabular}

Podemos establecer tres franjas claramente diferenciadas. 
- Franja A: delo-20\%

La primera franja corresponde a aquellos elementos que aparecen en menos de un 20\% de las definiciones; es decir, en 7 o menos definiciones. Si las analizamos se descubre que corresponden, con matices específicos, a cada uno de los conceptos que hemos analizado (la apariencia de movimiento, la presencia de imágenes fijas, el carácter didáctico, la temporalidad, la necesidad de codificación, ciencia o parte de la documentación, necesidad de codificación, conjunto de mensajes, diacronía, dualidad, su finalidad, la necesidad de un equipo adecuado para su reproducción, entre otros).

- Franja B: del 21 - 40\%

Esta segunda franja se corresponde con aquellos términos que aparecen entre un $21 \%$ y un $40 \%$; es decir, entre aproximadamente 8 y 15 veces. Dentro de esta franja encontramos tres posibilidades: a) que no se cuente con la banda de sonido, b) que la percepción se realice por medio de los sentidos de la vista y del oído c) y por último, que haya una fijación en un soporte físico, cualquiera que éste sea.

- Franja C: del 41 - 100\%

Esta franja se corresponde con los elementos más importantes debido a que la encontramos entre un 40 y un $100 \%$ de las definiciones, lo que implica que éstas aparecen aproximadamente entre 16 y 37 veces. En esta franja encontramos tres elementos: a) sonido (registro sonoro), b) imagen en movimiento c) y simultaneidad o sincronización de imagen y sonido. Se trata de tres elementos que definen al objeto de trabajo en los Sistemas de Información Documental Audiovisual. 


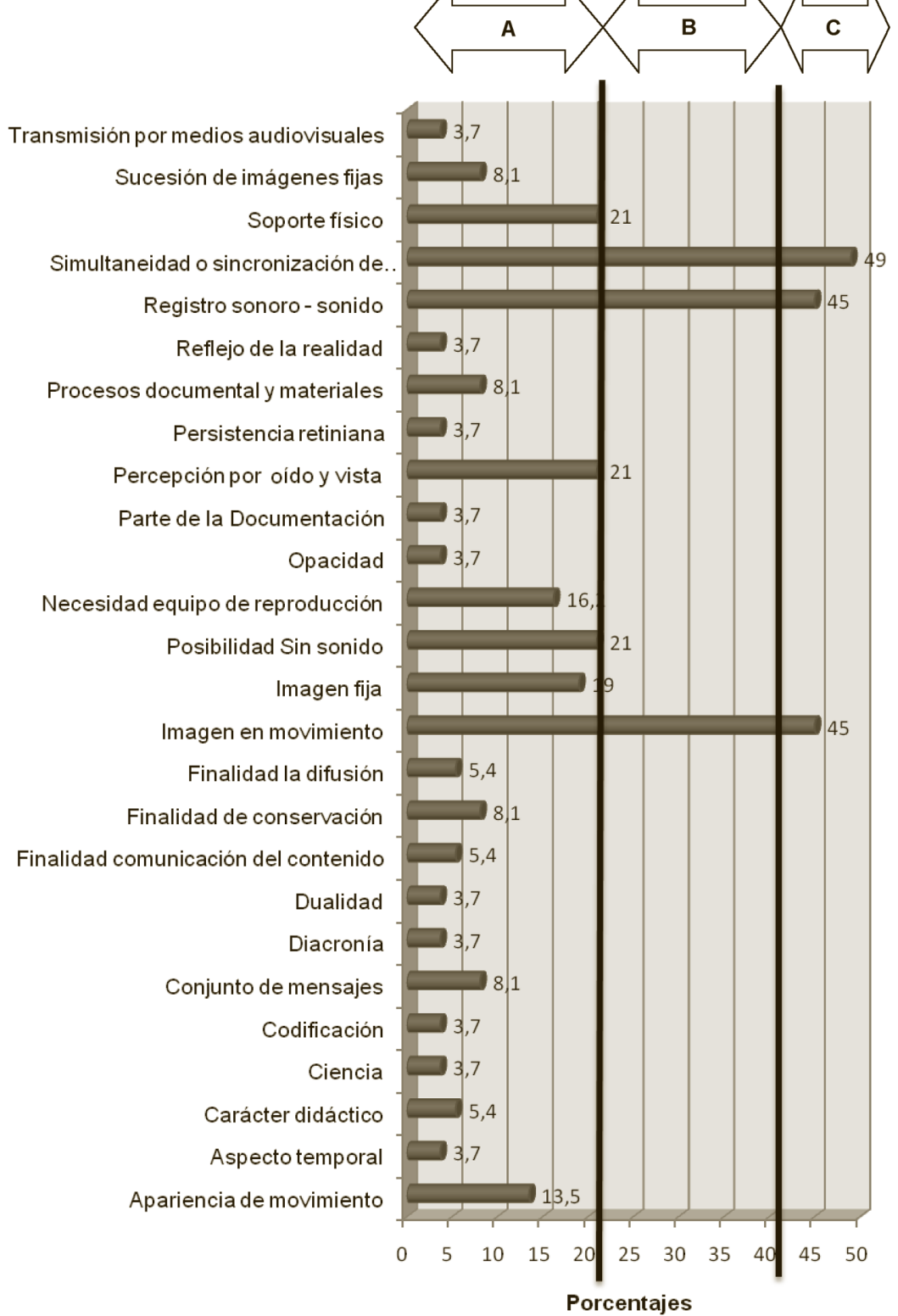




\section{Conclusiones}

A la vista de las definiciones aportadas por los más importantes autores e instituciones y extrayendo los elementos más relevantes, una vez contabilizada su repetición y consistencia conceptual, la definición propuesta por el equipo de trabajo sería la que a continuación se desarrolla:

Documento de imagen en movimiento televisivo:

Aquél generado por televisión y tratado en los Sistemas de Información Documental Audiovisual, que contiene imágenes en movimiento y sonido sincronizados, con la posibilidad de que no aparezca la banda de sonido, fijados en un soporte físico cualquiera que éste sea y que percibimos por los sentidos de la vista y del oído.

De dicha definición se extrapola:

- Que la institución de la cual emana dicha documentación es la televisión.

- Que dicho material es tratado en lo que se considera un Sistema de Información Documental de carácter audiovisual, entendiendo éste dentro de la Teoría de la Gestión de Sistemas.

- Que el concepto de documento en televisión "imagen en movimiento televisivo" suele contar en la práctica totalidad de los casos con sonido que acompaña a la imagen (aunque suele ser la imagen la que acompaña al sonido) en la práctica totalidad de los casos. No obstante, se deja abierta la casuística para entender que los documentos televisivos pueden carecer del audio por cortapisas legales o problemas técnicos en cuanto a la captación.

- Que tal material debe ser conservado en un soporte para gozar así de la naturaleza de perdurabilidad, accesibilidad y difusión, independientemente de cuál sea este soporte (analógico o digital) e independientemente del formato de captación. Su inclusión en las redes de telecomunicaciones ha potenciado su difusión pero no su forma de tratamiento, aunque sí es posible que se traduzca en nuevos paradigmas de gestión documental (Caldera, 2008).

- Que son necesarios los sentidos de la vista y del oído para entender el contenido total del documento de imagen en movimiento televisivo 


\section{Bibliografía}

Abad Tejerina, M.J. (1999), Imagen fija versus imagen en movimiento [en línea], disponible en: http://www.ucm.es/info/mupai/abad3. htm, [consultado: 16-09-08].

Agirrezaldegi Berriozabal, T. (1997), El uso de la documentación audiovisual en los programas informativos diarios de televisión, Bilbao, Universidad del País Vasco.

Alfonso I Noguerol, L. (1999). Manual de documentació audiovisual en ràdio y televisió, Valencia, Universitat.

Ander-Egg, E. (1995), Técnicas de investigación social, Buenos Aires, Lumen.

Caldera-Serrano, J (2008), "Changes in the management of information in audiovisual archives following digitazation: current and future outlook", en Journal of Librarianship and Information Science, 40 (1), p. 13-20.

, (2003), "Reflexiones sobre el concepto de documentación audiovisual y de imagen en movimiento en los Sistemas de Información de las televisiones" [en línea], Revista General de Información y Documentación, Vol 13, núm. 2, pp.193-202, disponible en: http://www.ucm.es/BUCM/revistas/byd/11321873/articulos/RGID0303220193A.PDF, [consultado: 19-09-07].

Caldera Serrano, J.; Nuño Moral, M.V. (2002), "Etapas del tratamiento documental de imagen en movimiento para televisión”, [en línea], Revista General de Información y Documentación, Vol. 12 Núm. 2, pp.375392, disponible en: http://www.ucm.es/BUCM/revistas/byd/11321873/ articulos/RGID0202220375A.PDF, [Consultado: 19-09-07] (2004), Diseño de una base de datos de imágenes para televisión, Gijón, Trea.

Cebrián Herreros, M. (1995), Información audiovisual: Concepto, técnica, expresión y aplicaciones, Madrid, Síntesis.

Corral Baciero, M. (1989), La documentación audiovisual en programas informativos, Madrid, Instituto Oficial de Radiotelevisión Española.

DUBLIN CORE (2003), Decision on proposal to add the terms "Moving Image" and "Still Image" to the DCMI Type Vocabulary [en línea], disponible en: http://dublincore.org/usage/decisions/2003/2003-02. Image-terms.shtml, [consultado: 19-09-07].

García Ejarque, L. (2000), Diccionario del archivero bibliotecario, Asturias, Trea.

IASA (2005), Reglas de catalogación de IASA: manual para la descripción de registros sonoros y documentos audiovisuales relacionados, $\mathrm{Ma}$ drid, ANABAD.

Hernández Perez, A. (1992), Documentación audiovisual: metodología para el análisis documental de la información periodística audiovisual, Madrid, Universidad Complutense, Facultad de Ciencias de la Información, Departamento de Periodismo III. 
IFLA (2004), Directrices para materiales audiovisuales y multimedia en bibliotecas y otras Instituciones [en línea], La Haya, IFLA Headquarters, disponible en: http://www.ifla.org/VII/s35/pubs/avmguidelines04-s.pdf, [consultado: 19-09-08].

Knight, G.; Mchugh, J. (2005), Preservation Handbook: Moving Image [en línea], disponible en: http://ahds.ac.uk/preservation/videopreservation-handbook.rtf, [consultado: 28-09-08].

López Thomé, E. (2000), “Documentación sonora”, en Moreiro, J.A. (coord.), Manual de Documentación Informativa, Madrid, Cátedra, p. 300.

López Yepes, A. (1992), Manual de documentación audiovisual, Pamplona, Universidad de Navarra.

López Yepes, J. (2004), Diccionario enciclopédico de ciencias de la documentación, Madrid, Síntesis.

Mendez, J. (1997), "Dimensiones asociadas con el papel de la imagen en material didáctico” [en línea], Perfiles educativos. Núm 75, enero-marzo, disponible en: http://redalyc.uaemex.mx/redalyc/ pdf/132/13207506.pdf, [consultado: 14-09-08].

Nuñez Fernandez, E. (1999), Organización y gestión de archivos, Gijón, Trea.

Ojeda Castañeda, G. (1992), Los archivos audiovisuales en las redes digitales de comunicación para la educación y la cultura [en línea], disponible en: http://ares.cnice.mec.es/informes/13/contenido/34.htm, [consultado: 14-09-08].

Orozco García-Mayorca, A. (1998), Apuntes sobre la organización y el análisis documental en los archivos audiovisuales [en línea], disponible en: http://www.patrimoniofilmico.org.co/docs/apuntesorg. rtf, [consultado: 24-09-08].

Pearce-Moses, R. (2005), A Glossary of Archival and Records Terminology [en línea], Society of American Archivists, disponible en: http://www.archivists.org/glossary/, [consultado: 28-09-08].

Real Academia de la Lengua (2001), [en línea], disponible en: www. rae.es., [consultado: 30-05-08].

Real Decreto Legislativo 1/1996, de 12 de abril, por el que se aprueba el Texto Refundido de la Ley de Propiedad Intelectual, regularizando, aclarando y armonizando las disposiciones legales vigentes sobre la materia [en línea], BOE núm. 97, de 22-04-1996, disponible en: http://civil.udg.es/normacivil/estatal/reals/Lpi.html.

Reitz, J.M. (2004), Online Dictionary for Library and Information Science [en línea], disponible en: http://lu.com/odlis/, [consultado: 28-09-08].

Rodríguez Bravo, B. (2004), "El documento audiovisual en las emisoras de televisión: selección, conservación y tratamiento" [en línea], Biblios, año 5, núm 20, octubre-diciembre, disponible en: http://eprints.rclis.org/archive/00003018/01/2004_29.pdf, [consultado: 19-09-08]. 
SEAPAVAA, SOUTHEAST ASIAN-PACIFIC AUDIOVISUAL ARCHIVE ASSOCIATION, disponible en: www.seapavaa.org, [consultado: 19-09-08]. UNESCO (1970), Glossary of Terms Related to the Archiving of Audiovisual Materials [en línea], Paris: UNESCO, disponible en: http:// portal.unesco.org/ci/en/files/7746/10448729330glossary.pdf/ glossary.pdf, [consultado: 27-09-08].

Valle Gastaminza, F. del (2004), Documentación audiovisual [en línea], Madrid: Universidad Complutense de Madrid, disponible en: http:/wwww.ucm.es/info/multidoc/prof/fvalle/tema12b.htm, [consultado: 19-09-08].

Victoria University of Wellington (2006), Glossary of Library Terms [en línea], disponible en: http://www.vuw.ac.nz/library/instruction/glossary.aspx, [consultado: 28-09-08]. 